\section{$\mathrm{Y}-12$}

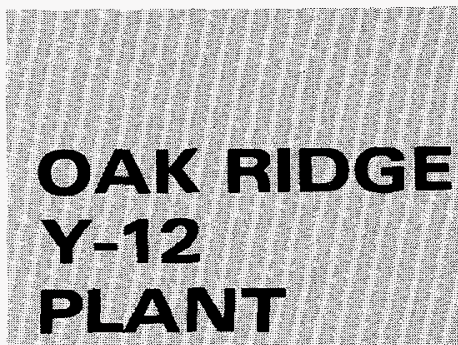

LOCKHEED MATTHA

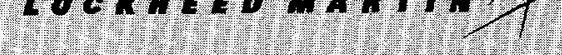

RECEIVED

FFR 281999

OSTI
Project Accomplishment Summary Report for

93-MULT-116-D1-04

\title{
NUMERICAL MODELING OF GIANT MAGNETORESISTANCE EFFECT FOR APPLICATION TO MAGNETIC DATA STORAGE
}

W. H. Butler

Lockheed Martin Energy Systems, Inc.

B. A. Gurney

IBM Almaden Research Center

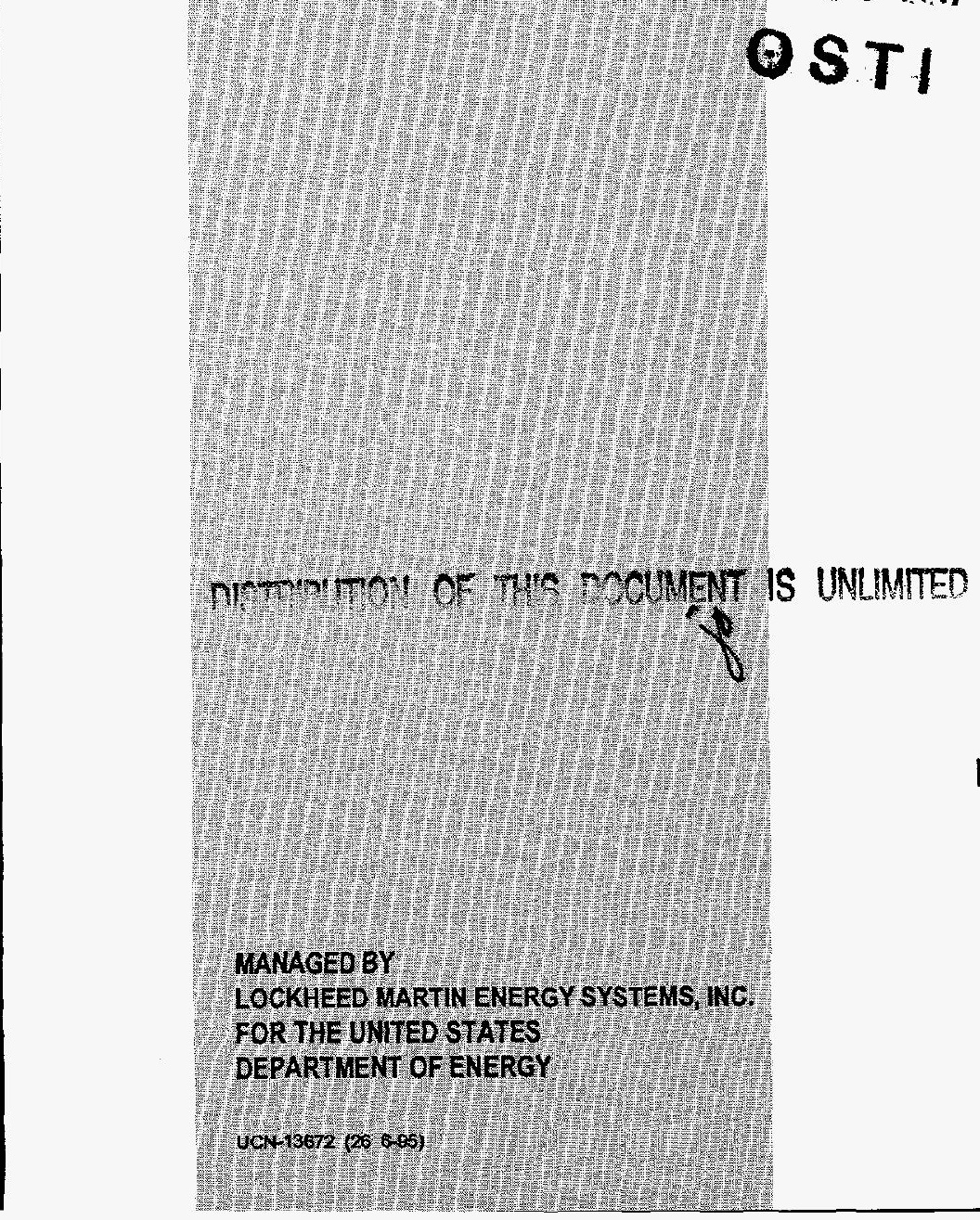

September 16, 1996

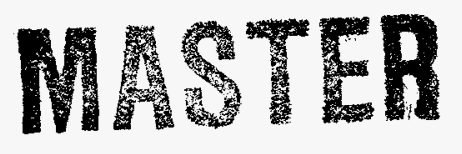

Approved for Public Release;

distribution is unlimited.

\author{
Prepared by the \\ Oak Ridge Y-12 Plant \\ managed by \\ LOCKHEED MARTIN ENERGY SYSTEMS, INC. \\ for the \\ U.S. DEPARTMENT OF ENERGY \\ under contract DE-AC05-84OR21400
}




\section{DISCLAIMER}

This report was prepared as an account of work sponsored by an agency of the United States Government. Neither the United States Government nor any agency thereof, nor any of their employees, makes any warranty, express or implied, or assumes any legal liability or responsibility for the accuracy, completeness, or usefulness of any information, apparatus, product, or process disclosed, or represents that its use would not infringe privately owned rights. Reference herein to any specific commercial product, process, or service by trade name, trademark, manufacturer, or otherwise, does not necessarily constitute or imply its endorsement, recommendation, or favoring by the United States Government or any agency thereof. The views and opinions of authors expressed herein do not necessarily state or reflect those of the United States Government or any agency thereof. 


\section{DISCLAMMER}

Portions of this document may be illegible in electronic image products. Images are produced from the best available original document. 


\section{PROJECT ACCOMPLISHMENT SUMMARY}

Title: $\quad$ Numerical Modeling of Giant Magnetoresistance Effect for Application to

CRADA Number: Y1293-0175

DOE TTI Number: 93-MULT-116-D1-04

Partner: $\quad$ IBM Almaden Research Center

\section{BACKGROUND}

The IBM Almaden Research center has many years of experience in magnetics and magnetoresistance. IBM built the first magnetic disk drive in 1954, the same year that one of its employees suggested that anisotropic magnetoresistance (AMR) could be used for magnetic field sensing. Until recently, read heads in commercial disk drives relied on inductive sensing. Currently, anisotropic magneotresistive heads are the state of the art for high performance commercial drives. All IBM disk drives in current production employ AMR sensing. Even AMR heads, however, will not be sensitive enough for the extremely high densities projected for the next two to five years.

Giant Magnetoresistance (GMR) is a change in electrical resistance that occurs in a magnetically inhomogeneous material when an applied magnetic field aligns the magnetic moments in different regions of the material. GMR was discovered in France in 1988 and was immediately recognized by IBM and others to be an important effect on which to base development of new magnetic sensors. IBM devised the first spin valves, the leading device for applying GMR to read sensors and to MRAM. The situation for Magnetic Random Access Memory (MRAM) devices is similar to that for disk and tape drive read sensors. Anisotropic magnetoresistance is currently used for sensing the state of the memory cell but AMR does not provide sufficient sensitivity to produce MRAM devices that are as fast ans as dense as semiconductor dynamic RAM.

The theory group is the Metals and Ceramics Division at Lockheed Martin Energy Systems, Inc. has a long experience in electronic structure calculations, in the theory of magnetism, and the theory of transport as well as experience in leading edge computations on massively parallel supercomputers. This made it possible for them to apply much more realistic models of GMR than other groups.

At the outset of this project, much was known empirically about GMR, however the theories then available were based on greatly oversimplified models of the electronic structure of the materials. It was difficult to understand the vast amount of experimental data in terms of a coherent theory and to understand how the use of different materials and structures affected GMR based devices.

\section{DESCRIPTION}

The giant magnetoresistance (GMR) effect allows the development of very small and sensitive devices for detecting and measuring magnetic fields. Such devices have many applications including the sensing of data on magnetic disk drives and in magnetic random access memory cells. This Cooperative Research and Development Agreement between Lockheed Martin Energy Systems and IBM Almaden Research Center was a joint experimental and theoretical program to obtain a better understanding of the giant magnetoresistance effect with the goal of optimizing the effect for application to magnetic data storage devices. The CRADA was successful in developing a detailed microscopic understanding of GMR and in pointing out strategies for increasing the GMR effect. 


\section{BENEFITS TO DOE}

Defense programs need magnetic memory devices that can withstand ionizing radiation and electromagnetic pulses. One such device, the MRAM or magnetic random access memory, stores information in the orientation of the magnetization in tiny cells of a magnetic film. The major limitation on the speed and information storage density of these devices is the sensitivity of the technique for non-destructively reading the data. Currently the anisotropic magnetoresistance effect is used for to sense the state of the memory cell. GMR, however, offers a much more sensitive technique for reading the data. It is estimated that an increase of a factor of two in the size of the GMR effect provide sufficient sensitivity for MRAM to compete successfully with semiconductor dynamic random access memory in terms of speed and density. Our models of GMR have suggested strategies for achieving this goal. Pursuit of this goal continues with funding from DARPA.

Defense programs also benefited from the development of techniques for parallel processing and their dissemination to DP laboratories. This CRADA was part of a three laboratory project. In addition to the Lockheed Martin Energy Systems, Inc. component, important roles were played by colleagues at Livermore and Sandia. Our Livermore colleague, in particular, learned much about parallel processing during his visits to Oak Ridge. Conversely important contributions to this work were provided by the other laboratories.

\section{ECONOMIC IMPACT}

This project provided a better understanding of GMR in terms of the underlying physical processes and their relation to actual materials and structures. The results may be applied to second generation disk read sensors and to first generation GMR-MRAM devices. This better understanding of GMR allows a more systematic and science based search for new GMR materials and structures. Exploitation of some of the discoveries under this CRADA, such as the wave guide effect may require improvements in film growth techniques. It is presently not possible to accurately predict the future job creation or revenue generation that will result from this CRADA.

\section{PROJECT STATUS}

The project has been completed.

\section{COMPANY SIZE}

IBM annual revenue is approximately $\$ 60$ billion. IBM has approximately 210,000 employees worldwide, approximately 4000 in Storage Systems Division, and approximately 500 at the Almaden Research Center.

CONTACTS

Lockheed Martin Energy Systems, Inc.:

William H. Butler

Lockheed Martin Energy Systems, Inc.

Oak Ridge, Tennessee 37831-6114

Phone: 423/574-4845

Fax: 423/574-7659

IBM Almaden Research Center

Bruce A. Gurney

IBM Almaden Research Center

650 Harry Road K66/C2

San Jose, California 95120 
Phone: $408 / 927-2351$

Fax: 408/927-3010

\section{TECHNOLOGY COMMERCIALIZATION}

It is generally recognized that expected increases in information storage density on hard disks will require the sensitivity of GMR sensors sometime during the next two to five years. The details of its commercialization plan are considered sensitive by IBM because many billions of dollars in revenue as well as leadership in the next generation of information storage devices may be at stake. 


\section{Distribution}

W. H. Butler, MS-6114, 4500-S

R. H. Ford, MS-8084, 9203

L. L. Horton, MS-6132, 4500-S

E. E. Bloom. MS-6117, 4500-S

D. F. Craig, MS-6132, 4500-S

W. P. Painter, MS-6416, 5002

Andy Stevens, MS-8015, 9704-2

Diane Bird, DOE

W. R. Wilburn, MS-8015, 9704-2

Laboratory Records, MS-6285, 4500-N

Y-12 Central Files, MS-8169, 9711-5 (3 copies)

Bruce A. Gurney, IBM Almaden Research Center, 650 Harry Road, San Jose, California 95120-6099 (5 copies) 